Florida International University FIU Digital Commons

\title{
The Effects of a Positive Youth Development Intervention on Problem Behavior Outcomes
}

Vanessa L. Madrazo

Florida International University, vlmadrazo@gmail.com

DOI: $10.25148 /$ etd.FI1 1072603

Follow this and additional works at: https://digitalcommons.fiu.edu/etd

\section{Recommended Citation}

Madrazo, Vanessa L., "The Effects of a Positive Youth Development Intervention on Problem Behavior Outcomes" (2011). FIU Electronic Theses and Dissertations. 437.

https://digitalcommons.fiu.edu/etd/437 


\title{
FLORIDA INTERNATIONAL UNIVERSITY
}

Miami, Florida

\section{THE EFFECTS OF A POSITIVE YOUTH DEVELOPMENT INTERVENTION ON PROBLEM BEHAVIOR OUTCOMES}

\author{
A thesis submitted in partial fulfillment of the \\ requirements for the degree of \\ MASTERS OF SCIENCE \\ in \\ PSYCHOLOGY \\ by
}

Vanessa L. Madrazo

2011 
To: Dean Kenneth Furton

College of Arts and Sciences

This thesis, written by Vanessa L. Madrazo, and entitled The Effects of a Positive Youth Development Intervention on Problem Behavior Outcomes, having been approved in respect to style and intellectual content, is referred to you for judgment.

We have read this thesis and recommend that it be approved.

$\begin{array}{r}\text { Mary Levitt } \\ \hline \text { Robert Lickliter } \\ \hline \text { William Kurtines, Major Professor }\end{array}$

Date of Defense: July 1, 2011

The thesis of Vanessa L. Madrazo is approved.

\begin{tabular}{r}
$\begin{array}{r}\text { Dean Kenneth Furton } \\
\text { College of Arts and Sciences }\end{array}$ \\
\hline Interim Dean Kevin O'Shea \\
University Graduate School
\end{tabular}

Florida International University, 2011 


\section{DEDICATION}

I dedicate this thesis to my family, to whom I am forever grateful. My success would not have been possible without their unwavering love and support. 


\section{ACKNOWLEDGMENTS}

I would like to thank the members of the Miami Youth Development Project for their support throughout this process. I would especially like to thank Alan Meca for his assistance and Kyle Eichas for paving the way. I am also thankful for the members of my committee, whose feedback and encouragement have helped push things along. I would like to thank Dr. Kurtines for sharing his expertise over the development of this project, and for his patience and guidance. Finally, I am very grateful for Henry and his understanding while I committed time and energy to this project. 


\title{
ABSTRACT OF THE THESIS \\ THE EFFECTS OF A POSITIVE YOUTH DEVELOPMENT INTERVENTION \\ ON PROBLEM BEHAVIOR OUTCOMES
}

\author{
by \\ Vanessa L. Madrazo \\ Florida International University, 2011 \\ Miami, Florida \\ Professor William Kurtines, Major Professor
}

This study reported an Outcome Mediation Cascade evaluation of the Changing Lives Program (CLP), a positive youth intervention. This study examined the effects of participation in the CLP on positive outcomes (Personal Expressiveness and Well-Being) and negative outcomes (Internalizing and Externalizing problem behaviors) as mediated by Identity Distress. 137 females and 101 males comprised the sample of this study, which draws from archival data of adolescents in alternative high schools in Miami. Findings indicated that the hypothesized model fit the data $\left(\chi^{2}(11)=14.544, p=.020\right.$; RMSEA $=.04 ; \mathrm{CFI}=.995 ;$ SRMR $=.028)$. Findings also provided preliminary evidence consistent with the hypothesis that in addition to having effects on targeted positive outcomes, PYD interventions are likely to have progressive cascading effects on untargeted problem outcomes. 


\section{TABLE OF CONTENTS}

CHAPTER

PAGE

I. INTRODUCTION

The Current Study

Mediator

Identity Distress

Positive Outcomes

Personal Expressiveness $\quad 13$

Well-Being

Problem Behavior

II. METHODOLOGY 15

$\begin{array}{ll}\text { Participants } & 15\end{array}$

$\begin{array}{ll}\text { Measures } & 18\end{array}$

$\begin{array}{ll}\text { Identity Distress } & 18\end{array}$

$\begin{array}{lr}\text { Personal Expressiveness } & 19\end{array}$

Well-Being 19

Internalizing and Externalizing Behaviors 20

Demographic Moderators $\quad 21$

III. PROCEDURES 21

Assessment Procedure $\quad 22$

Data Analytic Plan $\quad 22$

Data Analytic Strategy 22

Assessing Measurement Concerns 23

Measurement Error 23

Factor Structure of Multiple Item Measures 23

Model Fit Strategies $\quad 23$

Indices of Model Fit 23

Assessing Potential Moderators 23

Clustering 25

IV. RESULTS 25

Preliminary Analyses 25

Descriptive Statistics 25

Main Analyses 26

Outcome and Moderation Analyses 26

Hypothesized Direct Intervention Effects 26

Hypothesized Effects on Problem Outcomes 27

Hypothesized Cascade Effects 27 
$\begin{array}{ll}\text { V. DISCUSSION } & 27\end{array}$

VI. LIST OF REFERENCES 30

$\begin{array}{lll}\text { VII. APPENDICES } & 34\end{array}$ 


\section{LIST OF ABBREVIATIONS}

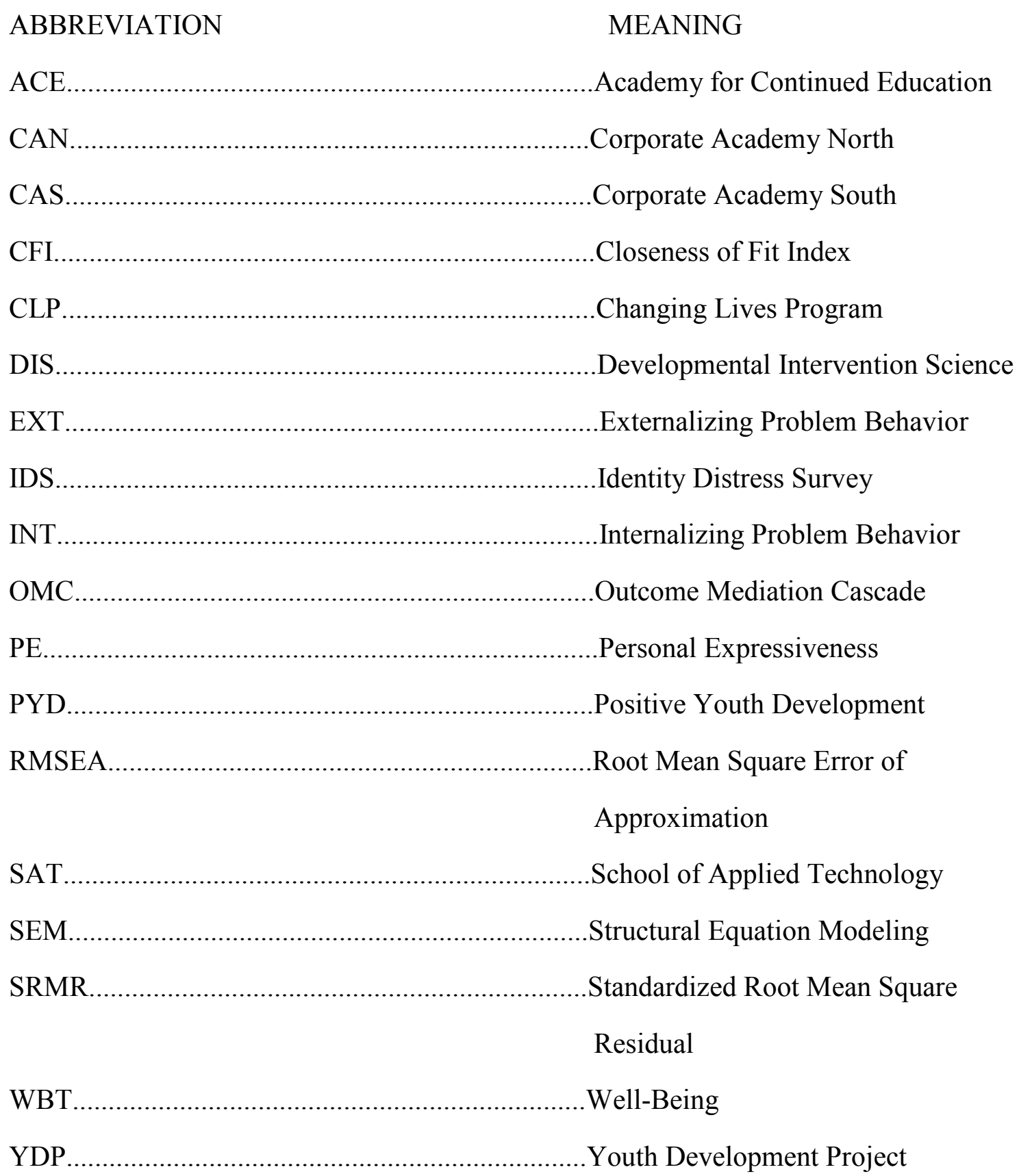




\section{INTRODUCTION}

A review of the literature on identity shows that the field has focused on characterizing the process of identity development (Eichas, 2008), resulting in the emergence of two main perspectives, namely the belief that identity formation is a process of creation (Berzonsky, 1986) and the belief that identity formation is a process of discovery (Waterman, 1984). According to Schwartz (2002), the creation perspective depicts the self as a construction of the individual, such that the individual actively constructs the self through rational and identity-related choices that involve selecting from alternatives that are presented by the individual's context (Schwartz, 2002; Eichas, 2008). Self-construction identity processes such as these are associated with thoughtful and objective considerations of present alternatives (Eichas, 2008). In contrast, the discovery perspective proposes that there is a pre-existing or "optimal" self that must be discovered (Eichas, 2008; Schwartz et al., 2005). Identity processing that is selfdiscovering in nature is related to the degree that an individual feels that an activity or decision resonates with one's true self, or "daimon" which consists of the unique set of capabilities and talents that exist within an individual (Eichas, 2008).

The self-construction and self-discovery perspectives represent different opinions on the role of agency in identity formation. Until recently, the two perspectives were treated as mutually exclusive points of view because they espoused conflicting views on the nature of the self (Eichas, 2008; Waterman, 1984; Berzonsky, 1986). Nevertheless, current research suggests that there may be common ground between the selfconstruction and self-discovery perspectives on identity formation processes (Schwartz, 
2002; Soenens et al., 2005) and attempts have been made to develop a model of identity formation that incorporates both approaches to identity formation (Schwartz, 2002).

Such attempts to redefine the nature of identity formation have affected the field of positive youth development (PYD) as well. A recent review of PYD programs reflects the growing importance of identity within the positive youth development movement, which maintains that a clear and positive identity is an important domain of development (Catalano, Berglund, Ryan, Lonczak, \& Hawkins, 1999; Montgomery, Kurtines, FerrerWreder, Berman, Lorente, Briones, et al. 2008; Ferrer-Wreder, Montgomery, \& Cass Lorente, 2003; Montgomery et al., 2008; Montgomery \& Sorell, 1998; Catalano, Berglund, Ryan, Lonczak, \& Hawkins, 2004). The current study presents an evaluation of a PYD intervention and its effects on positive and problem outcomes as mediated by identity distress. The Changing Lives Program (CLP) is a PYD intervention that enhances the competence of its participants by promoting positive change in core domains of psychosocial development such as sense of self and identity. In order to achieve this goal, the CLP must perform the challenging task of intervening at the level of identity while promoting positive change in youth.

The Miami Youth Development Project (YDP) is a youth development program that utilizes an outreach research model in order to serve the needs of Miami's multiproblem youth. It draws upon descriptive and explanatory knowledge in order to promote long-term developmental change in self and identity among adolescents (Kurtines \& Silverman, 1999; Kurtines, Montgomery, Eichas, Ritchie, Garcia, \& Albrecht et al., 2008). The Changing Lives Program (CLP) is a community-based intervention that is part of the Miami YDP and serves as a community-supported and selective/indicated 
program for multi-ethnic, multi-problem at risk youth in urban alternative high schools (Eichas, 2010). Its primary intervention goal is to empower youth to enact positive change in their lives, which is facilitated by allowing the participants to take an active role in the intervention while the interventionist becomes a co-learner in the process of developing alternatives to negative life outcomes (Montgomery et al., 2008). Extensive reviews in the identity development literature support the merits of promoting positive identity and sense of self through positive youth development interventions (Benson \& Saito, 2000; Catalano et al., 1999, 2004; Lerner, 2005; Lerner et al., 2005).

The Changing Lives Program also employs the concept of mastery experiences as a catalyst for positive change. A mastery experience occurs when an individual has a sense of agency related to his or her understanding of the outcomes of self-selected and self-directed transformative activities. Youth who participate in self-directed behavior that result in mastery experiences are more likely to engage in future transformative processes by drawing connections between their goals and how to achieve them (Montgomery et al., 2008), and can also "gain greater access to and control over resources and gain mastery over their lives" (Zimmerman, 1995, p. 583). Mastery experiences and the changes they prompt empower troubled youth because this type of change is believed to promote the positive development of the steering mechanism that directs the adolescents' life course and serves as their core sense of self and identity (Elder \& Shanahan, 2006; Montgomery, Kurtines, et al., 2008). Thus the mastery experience is a critical component of the CLP intervention that functions as a vehicle through which the positive change occurs. 
Various elements of theory inform the work of the Changing Lives Program. The CLP's counseling services draw from the transformative pedagogy of Paulo Freire (1983; 1970) and the multicultural counseling theory of Sue and Sue (2003) for guidance on strategies to enhance the critical consciousness of marginalized people. In accordance with this goal, the CLP operates under the assumption that young people are capable of experiencing positive development and should be viewed as resources to be developed rather than problems to be managed (Montgomery et al., 2008; Lerner, Lerner, Almerigi, Theokas, Phelps, \& Gestsdottir et al., 2005). The intervention framework of the CLP employs a participatory transformative intervention approach that extends and refines the psychosocial developmental concepts of self and identity and sociological life course theory in order to include the aforementioned concept of mastery experiences (Eichas, 2010; Montgomery, Kurtines, et al., 2008; Erikson, 1968; Elder, 1998; Bandura, 1997). Transformative and co-participatory, the approach of the CLP emphasizes the creation of a context in which students can take an active role in the counseling process and become experts with a greater sense of control, responsibility and insight in their lives (Montgomery et al., 2008). The developmental framework of the CLP and subsequent outreach with troubled adolescents are also informed by the psychosocial developmental theory of Erikson and the life course theory of Elder (Erikson, 1968; Elder, 1998)

\section{The Current Study}

In several ways the current study makes a unique contribution to the existing literature on positive youth development. Building upon preliminary studies, the current study takes the next logical step in trying to identify mediated cascade effects on untargeted problem outcomes that are empirically predictable but not currently 
hypothesized in the literature. By including well-being as a positive outcome, the current study further expands upon previous work, as this has not been previously examined as it relates to the CLP. The Developmental Intervention Science (DIS) approach integrates the fields of developmental science and treatment science with the overall goal of assessing whether positive youth development intervention strategies include positive effects on problem outcomes (Kurtines et al. 2008a, b; Eichas et al, 2010). By evaluating the CLP from a DIS perspective, the current study also contributes to existing knowledge.

In order to successfully examine intended and unintended effects of the CLP, the current study utilizes an Outcome Mediation Cascade (OMC) model in order to test hypothesized effects. The OMC model is presented in Figure 1 using standard SEM representation. Figure 1c depicts the OMC model, which serves as an extension of the outcome mediation model (Figure 1b), which itself builds upon the traditional comparative outcome model (Figure 1a) in order to include mediation. An integrated model such as the OMC helps evaluate the empirical intersection between intervention and developmental processes (Eichas, 2010). The basic premise for investigating cascade effects relates to the fact that interventions that target change in positive outcomes do not only enhance adaptive functioning, but may also "spillover" and contribute to the reduction of symptoms in the untargeted problem outcome domains. By choosing a model through which such effects can be examined, the current study contributes to existing knowledge regarding unintended effects of positive youth development interventions.

While the OMC model is useful from an application standpoint, it is also advantageous from a theoretical point of view. The model examined in the current study 
includes hypothesized developmental cascade effects that are informed by the literature on developmental psychopathology (Cicchetti \& Cohen, 2006). These developmental cascade effects are believed to take place when a function in one domain spills over and influences functioning in another domain (Masten et al., 2005). Furthermore, by including the cascade effects in the conceptual model (see Figure 2), the evaluation in the current study attempts to capture the spreading effects that occur as a result of dynamic interactions that take place over time (Masten et. al, 2005). That notwithstanding, the results of a comprehensive intervention strategy that acts on multiple domains does not answer the question of whether or an individual intervention strategy that is nested within the intervention package has an effect on a specific outcome domain, even though PYD interventions are generally evaluated with multi-intervention strategy/multi-outcome domain designs (Eichas, 2010). When coupled with the use of an appropriate evaluation model such as the one described below, a narrowband positive youth development intervention may help identify mechanisms of change though which directed intervention strategies may contemporaneously or progressively generate differential outcomes in specific domains (Eichas, 2010).

In addition to the benefits of examining cascade effects, there are many advantages of conducting research that is longitudinal as opposed to cross-sectional in nature. For example, dynamic systems theory posits that change in one area of functioning can therefore initiate a sequence of events or consequences that may lead to other changes, thus ultimately resulting in significant developmental effects (Masten et. al, 2005). By examining the developmental cascade effects it becomes easier to identify the specific change mechanisms though which prevention and developmental 
intervention strategies generate outcomes in specific domains. Since positive and problem intervention strategies may lead to interactions that involve moderator and mediator variables, the current study examines the CLP's intervention strategies by using a full range of evaluation information, including direct, indirect, and cascade effects.

The current study extends the work of Eichas (2010) by facilitating the identification of change processes though which intervention strategies may generate differential outcomes in specific outcome domains. Direct and mediated effects of participation in the CLP on the identity mediator Identity Distress (IDS); the positive outcomes of Personal Expressiveness (PE) and Well-Being (WBT); and the problem behaviors of Internalizing (INT) and Externalizing (EXT) behavior are measured.

Although significant research has been done on the effects of prevention interventions on problem behaviors, the evidence regarding effects of PYD interventions on problematic outcomes is scant or nonexistent (Schwartz et al., 2007). Overlapping effects may also surface as related consequences of a PYD intervention such as the Changing Lives Program. The current study addresses this shortcoming in the literature by including problem behaviors in its analysis. In 2002, Catalano et al noted that the mechanisms which yield risk and protective factors may influence positive youth development as well as problem behavior (Eichas, 2010). The causal effects that are generated by both positive and problem intervention strategies are furthermore likely to follow complex pathways as opposed to effects that flow directly from the positive intervention to positive outcomes or from the positive intervention to problem outcomes (Eichas, 2010). By investigating the developmental processes that underlie the CLP, the 
current study highlights the manner in which the intervention operates on both positive and problem behavioral outcomes.

In his 2005 study, Keyes investigated the complete state model of mental health and interpreted his results to indicate that the absence of mental illness is not equal to the presence of mental health. Keyes also posited that it is dubious to assume that youth who do not suffer from mental illnesses are consequently mentally healthy (Keyes, 2006). Thus the concept of well-being includes the evaluations and declarations that individuals make about the quality of their lives that are based on the review, weighting, and summation of the quality of experiences, relationships, and other culturally relevant and valued ways of functioning in life (Keyes, 2006; Diener, Suh, Lucas \& Smith, 1999; Keyes, Shmotkin, \& Ryff, 2002).

In order to develop a sense of self and identity, an individual must consolidate several facets of his persona such as drives, abilities, beliefs, and individual history. This task is particularly challenging during adolescence, which is a time of increased vulnerability and potential for development (Waterman, 1999). Intensified identity exploration such as this is also known as the identity crisis (Adams et al., 2001; Waterman, 1999). It is considered a normal developmental challenge during adolescence that allows for the finding, assessing, and establishing of identity commitments.

In order to evaluate developmental intervention cascades, it is necessary to include a single intervention strategy, at least one mediator, and in more than one outcome domain (see Figure 1). The mediation component of the model was used to evaluate possible change mechanisms by empirically investigating whether intervention strategies that aim to promote positive youth development outcomes also generate 
differential change in both targeted positive outcomes and untargeted problem outcomes (Eichas, 2010). Whether PYD interventions promote cascading developmental changes that eventually result in directional change with regards to problem outcomes has not been addressed in the PYD intervention literature (Eichas, 2010); however, Masten et. al (2005) have concluded that improved knowledge of what, when, and how cascades occur will lend itself to more strategic interventions. Therefore the current study also lends itself in assisting to develop more streamlined interventions that target positive youth development.

Figure 3 depicts the hypothesized effects of the model. Drawing on results reported by Albrecht (2007), it is hypothesized that participation in the CLP will have a positive effect on the mediation variable IDS (path C) and the outcome variable of PE (path B), findings previously reported using data from the CLP (Albrecht, 2007; Eichas et al., 2010). Although WBT has not been included in previous CLP studies, a large literature exists supporting a sense of well being as a positive developmental outcome (Schwartz et al., in press; Park, 2004; Keyes, 2006). For this reason, it is hypothesized that participation in the CLP will result in a positive direct effect on total well-being (path A). Although the direct and indirect effects of CLP on well-being and its direct and indirect cascading effects on problem outcomes have not yet been examined, the positive outcomes (PE, WBT) are hypothesized to have negative associations with the problem outcomes of internalizing problem behavior (INT) and externalizing problem behavior (EXT; paths $\mathrm{N}, \mathrm{O}, \mathrm{H}, \mathrm{I}$ ), while identity distress is hypothesized to have a positive association with the problem behaviors of INT and EXT (paths K, L, M, G). 
With regards to demographic variables, the current study includes ethnicity and gender as possible moderators. Because gender roles tend to vary between different cultures (Schwartz \& Montgomery, 2002; Sorrel \& Montgomery, 2001; Cole, 1998), it is reasonable to believe that intervention outcomes may be moderated by gender and ethnicity (Albrecht, 2007). The effect of gender and ethnicity on intervention outcomes is included in the current study analysis although no hypotheses are made in terms of directionality of effects.

\section{Mediator}

\section{Identity Distress}

While defining one's identity is a normal part of life, it can be problematic for young people who experience identity distress and may be comorbid with symptoms of psychological maladjustment (Berman, Montgomery, \& Kurtines, 2004; Hernandez, Montgomery, \& Kurtines, 2009). The transition from adolescence to adulthood has also become more difficult to navigate because of the growing complexity of society, and a relationship has been found between some facets of identity and alcohol, drug use (Berman, Montgomery, \& Kurtines, 2004; Schwartz et al., 2007). Identity exploration (or crisis) has been described as the "work" of the identity process and has been consistently found to co-occur with problematic outcomes (Grotevant, 1987; Eichas, 2010; Kidwell et al., 1995; Luyxck et al., 2006; Schwartz et al., 2008).

The theoretical literature on identity suggests that the identity crisis creates opportunities for the adolescent to discover activities that are personally expressive (Schwartz, 2001) and to explore the level of fit between life goals and his or her unique potentials, capabilities, and interests (Eichas, 2010). Difficulty in defining one's identity 
is common among young people and it is considered a normal occurrence that generally takes place during the transition to adulthood. In some cases, however, the difficulty may become so overwhelming that it interrupts the normal course of the adolescent's psychosocial development (Berman, Montgomery, \& Kurtines, 2004). The unease that follows is referred to as identity distress, and its distinguishing feature is the person's inability to integrate aspects of the self, such as long-term goals, choice of career, patterns of friendship, and sexual orientation (APA, 1987; 1994).

Although many measures of identity capture positive aspects of identity formation, most fall short of assessing the distress that is associated with the process of identity formation (Hernandez et al., 2006). While the presence of an excess of identity distress can hamper development, a lack of identity-related distress may suggest a lack of engagement in identity exploration because self-relevant experiences are unavailable (Albrecht, 2007). The Identity Distress Survey (IDS) was created in order to examine discomfort in individuals who experience difficulties in maintaining or developing an identity (Berman, Montgomery, \& Kurtines, 2004). The IDS is indicated for use in discovering associations between identity formation and psychological functioning, and may aid in the prevention or amelioration of identity distress (Hernandez et al., 2006). Research in the field has shown that identity confusion is associated with behavior problems while a coherent sense of personal identity is protective against psychological distress (Schwartz, Zamboanga, Weisskirch, \& Wang, 2010; Adams et al., 2001; Schwartz, Pantin, Prado, Sullivan, \& Szapocznik, 2005; de Goede, Spruijt, Iedema, \& Meeus, 1999). Previous research using data from the Miami Youth Development Project has shown that approximately one third of adolescents reported moderate, severe, or very 
severe upset, distress, and/or worry with regard to a number of identity relevant domains, including sexual behavior, religion, values and beliefs, and group loyalties (Hernandez et al., 2006; Albrecht, 2007). The current study uses the IDS in order to assess identity distress in adolescents who participate in the CLP intervention.

\section{Positive Outcomes}

\section{Personal Expressiveness}

Personal expressiveness (PE) is a widely used measure of positive identity development and is associated with many positive life outcomes such as competence, control, and self-esteem and it deliberately emphasizes self-determination and personal meaningfulness in identity choices (Csikszentmihalyi, 1975, 1990; Waterman 1993, 2004; Palen \& Coatsworth, 2007). Increases in personal expressiveness that co-occur with increases in identity distress may indicate more active participation in selfexploration regarding subjectively relevant aspects of life (Albrecht, 2007). Personal expressiveness is associated with eudaimonism, which stresses the importance of living according to one's authentic self and living "the meaningful life" (Gallagher, Lopez \& Preacher, 2009). Such meaning in life is achieved through participation in activities that are intrinsically motivated and emphasize self-realization with the understanding that an individual who engages these types of activities will sense that her life has meaning and will experience general happiness (Waterman 1993, 2007).

Personal expressiveness is likewise associated with the concept of mental health, which is defined as a combination of subjective well-being and personal growth (Compton, Smith, Cornish \& Qualls, 1996). Current research has also revealed that an association exists between personal expressiveness and positive psychological adjustment 
in high school adolescents. Personal expressiveness has been linked to high levels of adolescent-reported psychological well-being and low levels of adolescent-reported problem behavior. Nevertheless, as many as $20 \%$ of young people ages $16-17$ report having experienced a disorder related to mood, anxiety or substance use (Palen \& Coatsworth, 2007; Keyes, 2006). By investigating PE as a positive outcome variable, the current study contributes to the literature on general mental health as well as positive youth development. The current study includes the Personally Expressive Activities Questionnaire (PEAQ; Waterman, 1993) as a means of assessing personal expressiveness.

\section{Well-Being}

Well-being is a concept that is strongly associated with mental health. Keyes (2007) cited the World Health Organization (WHO) in defining mental health as a state of well-being where an individual can discover his or her own capacities and talents. Keyes $(2002,2007)$ defined mental health as a syndrome of one's symptoms of subjective well-being or a complete state where an individual does not exhibit pathology but experiences flourishing with high levels of emotional, psychological and social wellbeing. Thus Keyes (2007) defines complete mental health as the absence of pathology and the presence of flourishing, which is considered a more useful focus of study than languishing alone or flourishing alone. Actively fostering activity-related identity experiences for youth may be likewise related to a greater sense of psychological wellbeing (Palen \& Coatsworth (2007). The current study involves data that accounts for the presence of social, psychological, and emotional well-being which are reflections of three distinct but correlated latent factors (Keyes, 2005). Items assessing psychological, social 
and emotional well-being adapted from the Panel Study of Income Dynamics (PSID-CDS II; Mainieri, 2006) will be used in this study to represent the concept of well-being (WBT).

\section{Problem Behaviors}

The current study examines the effects of a positive youth development intervention on positive behavioral outcomes as well as the unintended cascade effects that it may have on problem behaviors. Problem behaviors are those actions that are understood as internalizing, such as depression or anxiety or externalizing behaviors, such as substance abuse or aggression.

\section{METHODOLOGY}

\section{Participants}

Students attending alternative high schools in Miami-Dade County, Florida served as participants in this study. Recruitment of students followed the standards of the Changing Lives Program (CLP). The CLP is a positive youth development program that takes place in four alternative high schools, including Corporate Academy North (CAN), Corporate Academy South (CAS), Academy for Community Education (ACE) and School for Applied Technology (SAT). Students enroll in alternative high schools because they exhibit behavior problems, academic issues, or other difficulties that may impede chances for success at their neighborhood high school. Group Facilitators at each school engage participants in weekly group sessions that focus on anger management, relationships, substance use or self-esteem (Hernandez et al., 2006). Students participated in the program via suggestion of a counselor, teacher or by self-referral. Participation in the program is voluntary, and students' grades are not affected if they do not participate. 
The current study draws from a sample within the CLP archival data file. These archives include data on specialty measures, as well as data on a core family of measures (group administered self-report, individually administered open ended and semistructured interview measures, etc.). Administration of core measures takes place during all data collection waves, while administration of specialty measures takes place at specific data collection waves for designated projects. The sampling strategy is to obtain information from students at alternative high schools where the CLP takes place in accordance with specifications regarding representation and participation in intervention groups.

The sample for this study was initially comprised of 259 White/Non-Hispanic, African-American, and Hispanic adolescents. Twenty one White/Non-Hispanic participants were not included in the final sample because of underrepresentation. Primary analyses were conducted on a sample of 238 African-American and Hispanic adolescents aged 14-19 who had completed pretest, posttest (Follow Up 1), and year-end assessments (Follow Up 2). The age range is 14-19 years of age, with most students falling between 15 and 18 years of age. Of the remaining 238 participants, 140 participated in the intervention condition, while 98 participated in a two-semester nonintervention, non-random comparison control condition.

In order to be included for analysis in the intervention condition, participants must have attended at least four sessions of the group counseling intervention during the semester in which they were randomly assigned to either the intervention (counseling) group or the control group. One hundred thirty seven females (87 African American, 50 Hispanic) and 101 males (52 African American, 49 Hispanic) submitted data that was 
included in the final sample. Among these individuals, $38 \%$ of annual family incomes were below $\$ 21,000$, while $17 \%$ were over $\$ 41,000$. Seventy-four percent of the participants had at least one parent who completed high school, $50 \%$ had two parents who completed high school, and $31 \%$ had at least one parent who completed a bachelor's degree. Data were collected in the Fall, Winter and Spring, allowing for analysis across three time points. Data were analyzed using Structural Equation Modeling.

Participants completed parent consent and student assent forms approved by university and M-DCPS IRBs before beginning assessments. The CLP counseling groups were organized and implemented through the school administration as part of each school's ongoing counseling program. All of the students who participated in the comparison control condition were randomly selected from a pool of students identified by the school counselors or administrators as not having participated in any of the counseling and guidance programs prior to or during the two semesters of their involvement with the Youth Development Project. Therefore, the criteria for inclusion in this study was participation in the intervention condition or control condition. Participants were not compensated for their involvement in the study.

Measures

\section{Identity Distress (IDS)}

The current study involves data gathered from the Identity Distress Survey (IDS; Berman, Montgomery, \& Kurtines, 2004), a 10-item scale based on diagnostic criteria of Identity Disorder as defined in the DSM-III-R. The IDS instrument contains seven items on 5-point Likert scales that gather information on distress as it relates to religion, beliefs, goals, career, sexual orientation, religion, values, and group loyalties. The items ask to 
what degree the participant has recently been upset, distressed, or worried with regards to long-term goals, career choices, friendships, sexual orientation, sexual behavior, religion, values, beliefs, and group loyalties. Two questions ask for an indication of global distress raised by these issues and last question assesses duration of distress over these issues. Hernandez, Montgomery, and Kurtines (2006) reported statistically significant correlations between IDS and other adjustment problems: antisocial behavior $(\mathrm{r}=.34)$, anxious/depressed symptoms $(\mathrm{r}=.36)$, hyperactive behaviors $(\mathrm{r}=.34)$, peer problems/social withdrawal $(\mathrm{r}=.38)$, and headstrong behaviors $(\mathrm{r}=.29)$. An evaluation of the IDS' Cohen's Kappa has shown high test-retest reliability $(\kappa=.82$; Berman, Montgomery, \& Kurtines, 2004). Cronbach's standardized alpha for the IDS items has been previously reported at .80 (Hernandez, Montgomery, \& Kurtines, 2006); analysis of a YDP sample indicates a value of .79 for Cronbach's alpha.

Personal Expressiveness (PE)

The Personally Expressive Activities Questionnaire (PEAQ; Waterman, 1995) is a 14-item self-report measure that includes three subscales indicating feelings of personal expressiveness, hedonic enjoyment, and flow challenge. The Waterman (1995) study used the feelings of personal expressiveness subscale (PE) as a measure of differential intervention outcome in the positive domain. When used with college students, the PE subscale of the PEAQ has shown good test-retest reliability and internal consistency ( $\alpha=$ .90; Waterman 1993), as well as convergent validity with other measures of identity and motivation (Palen \& Coatsworth, 2007). The PEAQ has been adapted for use in the evaluation of CLP by using questions to reference activities that are associated with the long-term life goals of the respondents. The PE subscale consists of six items and 
indicates the degree to which respondents feel that the pursuit of life goals is personally satisfying and expressive of their unique potentials. Items are rated on a 7-point Likert scale from 1 (strongly disagree) to 7 (strongly agree) and include items such as "When I do these activities, I feel like it's what I was meant to do" (Waterman, 1995). Waterman (2004) found significant correlations between PE scores and identity status and identity style, providing evidence of concurrent validity and an alpha reliability coefficient of .77 (Waterman 2005) for the PE subscale, which is .91 in the current study.

Well-Being (WBT)

The current study examines data on subjective well-being from items that are adapted from the Child Development Supplement II of the Panel Study on Income Dynamics (PSID-CDS II; Mainieri, 2006). These items are used to replicate Keyes' diagnosis of mental health (Keyes 2002, 2005a). The PSID-CDS II survey is administered on a national scale, which involves participation from children and adolescents ages 5 to18. The measure used in the current study consists of 13 items adapted from the PSID that collectively assess the three types of well being. The measure is scored on five-point Likert scales, ranging from 1 (almost never true) to 5 (almost never true) that are summed to create a score of overall well being. Keyes (2006) has reported Cronbach's alphas of $.84, .80$, and .78 for the scales of emotional well being, social well-being, and psychological well-being respectively in the PSID-CDS II sample. Analysis of a YDP sample indicates a Cronbach's alpha of .83.

Internalizing (INT) and Externalizing (EXT) Behaviors

The Behavior Problem Index (BPI; Peterson \& Zill, 1986) was used to assess internalizing and externalizing problem behaviors. The 32 items of the BPI were taken 
from the Achenbach Behavior Problems Checklist (Achenbach \& Edelbrock, 1981), a more extensive measure that is widely used with children and adolescents. The BPI items were included in the Panel Study of Income Dynamics - Child Development Supplement II (PSID-CDS II; Mainieri, 2006) in order to assess for a number of behavior problems occurring over the past 3 months, which were then scored for EXT and INT problem behaviors. The modification of the BPI used in the CLP was created for the purpose of obtaining self-reports of problem behaviors. Items were reworded to fit the format of selfreport, but the contents of the items did not change. Sample items include, "I cheated or told lies," "I cried too much," and "I was impulsive, or acted without thinking." Items are rated on a 3-point scale, labeled "often true," "sometimes true," or "not true". Items were reverse-coded prior to analysis, such that $1=$ "not true" and $3=$ "often true" in order to simplify interpretation. Mainieri (2006) reported Cronbach's alphas of .86 for EXT and .83 for INT in the PSID-CDS II sample. Cronbach's alphas for the present sample were .81 and .85 for the EXT and INT, respectively.

\section{Demographic Moderators}

The Background Information Form (BIF) is a record of demographic information completed by all participants in the YDP program. It provided the data used in analyses of gender as an exogenous moderator.

\section{PROCEDURES}

The intervention was implemented at the beginning of the academic year at each of the four alternative high schools. Each school was assigned one group facilitator, one co-facilitator, and one to two group assistants who were all students at Florida International University, and this structure was uniform across all high schools. As per 
the research design, only graduate level students currently enrolled in a doctoral or a masters level program in psychology could serve as group facilitators or co-facilitators. Group assistants were undergraduate psychology students who completed training on the proper procedures for administration of measures and tracking participants. The intervention groups functioned in a counseling capacity that utilized the participatory transformative approach that forms the basis of the CLP's intervention strategy (Montgomery, Kurtines, et al., 2008). The groups met for approximately 45 minutes to 1 hour every week for approximately 8 to 12 weeks in either the fall or spring semester.

\section{Assessment Procedure}

Undergraduate students in a psychosocial developmental psychology senior lab course administered assessments on participants in this study as fulfillment of data collection requirements for the class while other undergraduate students chose to participate by entering data. The undergraduates completed training every semester in order to serve as research trainees. In these trainings, graduate students emphasized issues of confidentiality, methods of assessment, dress code, high school regulations, and interviewing strategies. Assessments were conducted at three times during the MDPS school year on school grounds and during school hours at the four high schools. Assessments took place the week preceding the commencement of the semester sessions and the week after the end of each semester's sessions.

\section{Data Analytic Plan}

\section{Data Analytic Strategy}

To test the research hypotheses associated with specific research aims 1 and 2, a cross sectional analysis of the data was conducted within a structural equation modeling 
(SEM) framework with the use of AMOS 6.0. Structural Equation Modeling takes a confirmatory approach to structural analysis that allows the entire system of variables within the current model (Figure 3) to be statistically tested simultaneously (Byrne, 2001).

Assessing Measurement Concerns

\section{Measurement Error}

All of the constructs in the current model are associated with a single indicator. Therefore, this study will adopt the strategy suggested by Joreskog and Sorbom (1996) that involves constraining the error variances for each measure to values corresponding to a priori determined levels of reliability. Reliability levels will be based on alpha coefficients or previous research.

Factor Structure of Multiple Item Measures

All of the measures to be used in the current study are multi-item measures. The coefficient alphas and factor structures of the measures will be evaluated to ensure that they are consistent with their psychometric histories. The intercorrelations of variables will be routinely examined, and coupled with the results of confirmatory factor analyses, decisions will be made about combining indices or introducing latent constructs into the analysis.

Model Fit Strategies

Indices of Model Fit

Following the recommendations of Bollen and Long (1993), a variety of global fit indices will be used, including indices of absolute fit, indices of relative fit and indices of fit with a penalty function for lack of parsimony. First, the chi-square and its probability 
value (p-value) will be examined. The target $p$-value is greater than .05 , since the higher the p-value is, the closer the fit between the hypothesized model and model fit (Byrne, 2001). The comparative fit index (CFI) is an index of fit derived from the comparison of the hypothesized model with the independence model. A CFI value of greater than .95 will indicate model fit. The root mean square error of approximation (RMSEA) accounts for the error of approximation in the population. An RMSEA of less than .08 will indicate model fit. The standardized root mean square residual (SRMR) is the average value of standardized residuals derived from fitting the variance-covariance matrix of the hypothesized model to that of the sample data (Byrne, 2001). A SRMR of .05 or less will indicate model fit. In addition to the global fit indices, more focused tests of fit will be pursued.

\section{Assessing Potential Moderators}

A moderator is a third variable that affects the relationship between an independent variable and a dependent variable (Baron \& Kenny, 1986). Moderation is an approach to interaction analysis that requires the specification of a focal independent variable and a moderator variable (Jaccard \& Turrisi, 2003). Each of the moderator variables in this study are categorical variables. Therefore, it will be necessary to create dummy variables reflecting the presence or absence of each level of the moderator variables. Then, following the guidelines in Jaccard and Turrisi (2003), the predictor variables will be mean centered, and product terms will be created for each possible combination of moderator variables. These strategies will utilize the computer program ZumaStat. The issue of moderation will be approached in an exploratory fashion; interactions that are found to be significant will be included in the final model. 


\section{Clustering}

The data will be collected in different organizations/schools with a substantial number of persons within each organization/school, so there is the possibility of clustering effects. We will evaluate this by examining intraclass correlations and adjust for clustering if it seems necessary to do so, either by the introduction of covariates reflecting organization/school units, or the use of robust estimators available in the $\mathrm{M}$ Plus computer programs.

\section{RESULTS}

\section{Preliminary Analyses}

\section{Descriptive Statistics}

Table 1 presents descriptive statistics for the current study. Means and standard deviations for positive outcome variables are presented for the Pre-Test and Follow Up 1 (FU1) data collection timepoints. The means and standard deviations for problem outcomes variables are shown from the Follow Up 1 and Follow Up 2 (FU2) data collection timepoints. Table 1 includes descriptive statistics on the Identity Distress Survey (IDS); the items on well-being from the Panel Study on Income Dynamics

(WBT); the Personally Expressive Activities Questionnaire: Personal Expressiveness (PE); and the Behavior Problem Index: Internalizing (INT) and Externalizing (EXT) problem behaviors.

\section{Main Analyses}

Figure 3 the hypothesized Outcome Mediation Cascade (OMC) model, was evaluated using a Structural Equation Modeling (SEM) approach for modeling hypothesized causal pathways of intervention change. Model specification was guided by 
Figure two. Figure 4 presents the results for Model 1, including relations between the hypothesized mediator (IDS), the positive outcome variables (PE, WBT), and the two problem behavior outcome variables (INT, EXT) for the full sample.

\section{Outcome and Moderation Analyses}

Figure 3 provides results for the main outcome analyses, moderation analyses, and directionality of effect for the full sample. Table 2 presents the fit indices for major analyses. The overall chi square test of model fit of Model 1 was statistically nonsignificant, $\chi^{2}(11)=14.544, p=.20$. The RMSEA was .04, the SRMR was .028 , and the CFI was .995, which all indicate good model fit. The model in Figure 4 presents statistically significant paths in bold, while Table 3 presents the parameter estimates for the major analyses.

\section{Hypothesized Direct Intervention Effects}

As can be seen from Figure 4, the pattern of findings provided evidence of a significant relationship between participation in the CLP and change in IDS at Follow Up 1. The findings also showed a statistically significant effect of participation in CLP on INT at Follow-Up 2, while participation in CLP was associated with a marginally significant effect on EXT at Follow-Up 2. Participation in the CLP was associated with a statistically significant relationship on identity distress (IDS), the hypothesized mediator.

\section{Hypothesized Effects on Problem Outcomes}

Findings provided support for IDS as a mediator of the relationship between CLP and changes in INT, while a moderated mediated relationship was found between participation in the CLP, change in IDS at Follow Up 1, change in INT at Follow Up 1 and change in EXT at Follow Up Two. 


\section{Hypothesized Cascade Effects}

With regard to hypothesized cascade effects, that is, intervention effects in untargeted problem outcomes mediated by change in targeted positive outcomes, analyses provided support for three plausible causal chains that represent intervention cascade effects. The findings provided support for a cascade effect between CLP and INT as part of the pathways

\section{DISCUSSION}

The results of the statistical analysis yielded a complex picture with regards to the intended and unintended effects of the Changing Lives Program. Participation in the CLP was not associated with change in internalizing or externalizing problem behaviors at Follow Up 1. However, participation in the CLP was associated with a statistically significant $(p<.05)$ positive direct effect on internalizing problem behaviors at Follow Up 2 and a marginally significant direct effect $(p<.10)$ on externalizing problem behaviors, also at Follow Up Two. Results likewise show an indirect effect of participation in the CLP and externalizing problem behaviors at Follow Up 2 through the mediated moderated pathway of CLP $>$ IDS FU1 $>$ INT FU1 $>$ EXT FU2. The existence of direct effects of participation in the intervention on problem behaviors in addition to mediated moderated effects supports the hypothesis that participation in the CLP is related to change in unintended problem behaviors. In addition, the lack of direct effects of participation in the CLP on positive behavior outcomes supports the hypothesis that a positive youth development intervention such as the CLP does not necessarily operate on positive outcomes at all times, and PYD interventions should continuously be reviewed for effects on non-positive variables. 
Analysis of model fit to the data showed a marginally significant direct effect of condition on identity distress at follow up 1 . This finding is consistent with the work of Albrecht (2007) and lends support to the goal of the CLP, which is to engage youth in critically examining their current life course. Since participation in the intervention was associated with a significant positive change in identity distress, it follows that the Changing Lives Program is associated with unease in regards to matters of identity. Unease of this sort is associated with the identity crisis, which is regarded as a normative challenge during adolescent development that is marked by identity exploration and consolidation (Adams et al., 2001; Waterman, 1999). Thus the finding of a direct effect of condition on identity distress at Follow Up 1 serves to support the successful achievement of the Changing Lives Program intervention aims.

There are some limitations to consider regarding the current study. The length of time elapsed between Pre-test and Follow Up 2 is one academic year in high school. A period of 10 months is hardly a sufficient amount of time to ascertain the enduringness of developmental changes that take place over time. Although problem behaviors are possible external manifestations of developmental change, the findings would be better contextualized if data was taken on positive behaviors that represent positive functioning from a societal perspective, such as graduation rates or rates of employment. Because the sample was comprised of at-risk adolescents, there are limitations with regards to the generalizability of the findings to other populations. Total well-being represented a composite score that was derived of scores on subscales measuring emotional, psychological, and social well-being. Since these are related but not identical forms of well-being, the conclusions that can be drawn from the WBT measure are tenuous. Future 
studies should focus on separating the three forms of well-being and looking at them separately in order to better ascertain the effects, if any, of participation in the Changing Lives Program on the three types of well-being. 


\section{LIST OF REFERENCES}

Adams, G. R., Munro, B., Doherty-Poirer, M., Munro, G., Petersen, A. R., \& Edwards, J. (2001). Diffuse-avoidant, normative, and informational identity styles: Using identity theory to predict maladjustment. Identity, 1, 307-320.

Albrecht, R. E. (2005). An investigation of the effects of a school-based intervention on feelings of personal expressiveness in multi-problem youth. Unpublished Master's thesis. Florida International University, Miami.

Albrecht, R. E. (2007). A model of self-transformative identity development in troubled adolescent youth. Unpublished doctoral dissertation. Florida International University, Miami.

APA (American Psychiatric Association). (1987). Diagnostic and Statistical Manual of Mental Disorders, 3rd, revised (DSM-III-R). Washington, D.C.: APA Press.

APA (American Psychiatric Association). (1994). Diagnostic and Statistical Manual of Mental Disorders, 4th, (DSM-IV). Washington, D.C.: APA Press.

Benson, P. L., Mannes, M., Pittman, K., \& Ferber, T. (2004). Youth development, developmental assets, and public policy. In R. Lerner \& L. Steinberg (Eds.), Handbook of adolescent psychology (pp. 781-814). Hoboken, NJ: John Wiley \& Sons Inc.

Berman, S. L., Montgomery, M. J, \& Kurtines, W. M. (2004). The development and validation of a measure of identity distress. Identity: An International Journal of Theory and Research, 4, 1-8.

Berman, S., Kennerley, R. J., \& Kennerly, M. A. (2008). Promoting adult identity development: A feasibility study of a university-based identity intervention program. Identity: An International Journal of Theory and Research, 8, 139-150.

Berzonsky, M. D. (1986). Discovery versus constructivist interpretations of identity formation: Considerations of additional implications. Journal of Early Adolescence, 6(2), 111-117.

Berzonsky, M. D. (1990). Self-construction over the life-span: A process perspective on identity formation. In Neimeyer, G. J. and Neimeyer, R. A. (eds.), Advances in Personal Construct Psychology (Vol 1, pp. 156-186). Greenwich, CT: JAI Press.

Berzonsky, M. D. (1992). Identity style and coping strategies. Journal of Personality, 60, 771-788. 
Berzonsky, M. D. \& Sullivan, C. (1992). Social-cognitive aspects of identity style: Need for cognition, experiential openness, and introspection. Journal of Adolescent Research, 7, 140-155.

Bollen, K. \& Long, S. (1993). Testing structural equation models. Newbury Park: Sage.

Byrne, B. M. (2001). Structural equation modeling with AMOS: Basic concepts, applications, and programming. Mahwah, NJ: Laurence Erlbaum Associates, Inc.

Catalano, R. F., Berglund, M. L., Ryan, J. A. M., Lonczak, H. S., \& Hawkins, J. D. (2004). Positive youth development in the United States: Research findings on evaluations of positive youth development programs. The Annals of the American Academy of Political and Social Science, 591, 98-124.

Compton, W. C., Smith, M. L., Cornish, K. A., \& Qualls, D. L. (1996). Factor structure of mental health measures. Journal of Personality and Social Psychology, 71, 406-413.

De Goede, M., Spruijt, E., Iedema, J., \& Meeus, W. (1999). How do vocational and relationship stressors and identity formation affect adolescent mental health? Journal of Adolescent Health, 25, 14-20.

Diener, E., Suh, E. M., Lucas, R. E., \& Smith, H. L. (1999). Subjective wellbeing: Three decades of progress. Psychological Bulletin, 125, 276-302.

Eichas, K. R. (2008). Promoting self-construction and self-discovery processes: A multi-stage longitudinal comparative design stage ii evaluation of the changing lives program. Unpublished master's thesis. Florida International University, Miami.

Eichas, K. R. (2010). An investigation of multiple pathways of developmental intervention change. Unpublished doctoral dissertation. Florida International University, Miami.

Eichas, K. R., Albrecht, R. E., Garcia, A. J., Ritchie, R. A., Varela, A., Garcia, A. et al. (2010). Mediators of positive youth development intervention change: Promoting change in positive and problem outcomes? Child Youth Care Forum, published online April 20, 2010.

Erickson, E. H. (1968). Identity:Youth and crisis. New York: W. W. Norton.

Ferrer-Wreder, L., Montgomery, M. J., \& Lorente, C. C. (2003). Identity promotion, adolescence. In T. Gullotta \& M. Bloom (Series Ed.) \& G. R. Adams (Vol. Ed.), The encyclopedia of primary prevention and health promotion: Adolescent Volume (600-607). New York: Kluwer Academic/Plenum. 
Freire, P. (1983). Pedagogy of the oppressed. New York: Herder \& Herder. (Original work published 1970).

Gallagher, M. W., Lopez, S. J., \& Preacher, K. J. (2009). The hierarchical structure of well-being. Journal of Personality, 77, 1026-1049.

Hernandez, L., Montgomery, M. J., \& Kurtines, W. M. (2006). Identity distress and adjustment problems in at-risk adolescents. Identity: An International Journal of Theory and Research, 6, 27-33.

Jaccard, J., \& Turrisi, R. (2003). Interaction effects in multiple regression. Thousand Oaks, CA: Sage.

Joreskog, K. \& Sorbom, D. (1996). Users manual for LISREL. Chicago: Scientific Software.

Keyes, C. L. (2002). The mental health continuum: From languishing to flourishing in life. Journal of Health and Social Behavior, 43, 207- 222.

Keyes, C. L., Shmotkin, D., \& Ryff, C. D. (2002). Optimizing well-being: The empirical encounter of two traditions. Journal of Personality and Social Psychology, 82, $10007-1022$.

Keyes, C. L. (2003). Complete mental health: An agenda for the 21st century. In C. L. Keyes \& J. Haidt (Eds.), Flourishing: positive psychology and the life well-lived (pp.293-312). Washington, DC: American Psychological Association.

Keyes, C. L. (2005a). Mental illness and/or mental health? Investigating axioms of the complete state model of health. Journal of Consulting and Clinical Psychology, 73, $539-548$.

Keyes, C. L. (2005b). The subjective well-being of America's youth: Toward a comprehensive assessment. Adolescent \& Family Health, 4, 3-11.

Keyes, C. L. (2006). Mental health in adolescence: Is America's youth flourishing? American Journal of Orthopsychiatry, 76, 395-402.

Keyes, C. L. (2007). Promoting and protecting mental health as flourishing. A complimentary strategy for improving national mental health. American Psychologist, 62, 95-108.

Kurtines, W. M., Montgomery, M. J., Eichas, K., Ritchie, R., Garcia, A., Albrecht, R., et al. (2008). Promoting positive identity development in troubled youth: A 
developmental intervention science outreach research approach. Identity: An International Journal of Theory and Research, 8, 125-138.

Kurtines,W. M., \& Silverman,W. K. (1999). Emerging views of the role of theory. Journal of Clinical Child Psychology, 28, 558-562.

Lerner, R. M., Lerner, J. V., Almerigi, J. B., Theokas, C., Phelps, E., \& Gestsdottir, S. et al. (2005). Positive youth development, participation in community youth development programs and community contributions of fifth-grade adolescents: Findings from the first wave of the 4-h study of positive youth development. Journal of Early Adolescence, 25, 17-71.

Lerner, R. M., \& Overton, W. F. (2008). Exemplifying the integrations of the relational developmental system: Synthesizing theory, research, and application to promote positive development and social justice. Journal of Adolescent Research, 23, 245-255.

Luyckx, K., Soenens, B., Berzonsky, M. D., Smits, I., Goossens, L., \& Vansteenkiste, M. (2007). Information-oriented identity processing, identity consolidation, and well-being: The moderating role of autonomy, self-reflection, and selfrumination. Personality and Individual Differences, 43, 1099-1111.

Luyckx, K., Schwartz, S. J., Goossens, L., Soenens, B., \& Beyers, W. (2008). Developmental typologies of identity formation and adjustment in female emerging adults: A latent class growth analysis approach. Journal of Research on Adolescence, 18, 595-619.

Mainieri, T. (2006). The Panel Study of Income Dynamics Child Development Supplement: User Guide for CDS-II. Ann Arbor Michigan: The Institute for Social Research.

Marcia, J. E. (1966). Development and validation of ego-identity status. Journal of Personality and Social Psychology, 3, 551-558.

Marcia, J. E. (2001). A commentary on Seth Schwartz's review of identity theory and research. Identity: An International Journal of Theory and Research, 1, 59-65.

Muthén, L. K., \& Muthén, B. O., (2004). Mplus: The comprehensive modeling program for applied researchers. User's guide (3rd ed.). Los Angeles: Muthén \&Muthén.

Montgomery, M. J., \& Sorell, G. T. (1998). Love and dating experience in early and middle adolescence: Grade and gender comparisons. Journal of Adolescence, 21, $677-689$. 
Montgomery, M. J., Kurtines, W. M., Ferrer-Wreder, L., Berman, S. L., Lorente, C. C., Briones, E., Silverman, W., Ritchie, R., \& Eichas, K. (2008). A Developmental Intervention Science (DIS) outreach research approach to promoting youth development: Theoretical, methodological, and meta-theoretical challenges. Journal of Adolescent Research, 23, 268-290.

Palen, L-A. \& Coatsworth, J. D. (2007). Activity-based identity experiences and their relations to problem behavior and psychological well-being in adolescence. Journal of Adolescence, 30, 721-737.

Roth, J. L., \& Brooks-Gunn, J. (2003). What exactly is a youth development program? Answers from research and practice. Applied Developmental Science, 7, 94111.

Rinaldi, R. L. (2011). A developmental intervention science outreach research approach to promoting positive youth development. Unpublished doctoral dissertation. Florida International University, Miami.

Schwartz, S. J. (2001). The evolution of Eriksonian and Neo-Eriksonian identity theory and research: A review and integration. Identity: An International Journal of Theory and Research, 1, 7-58.

Schwartz, S. J. (2002). In search of mechanisms of change in identity development: Integrating the constructivist and discovery perspectives in identity. Identity, 2, 317-339.

Schwartz, S. J., Kurtines, W. K.,\& Montgomery, M. J. (2005). A comparison of two approaches for facilitating identity exploration processes in emerging adults: an exploratory study. Journal of Adolescent Research, 20, 309-345.

Schwartz, S. J., Pantin, H., Prado, G., Sullivan, S., \& Szapocznik, J. (2005). Family functioning, identity, and problem behavior in Hispanic immigrant early adolescents. Journal of Early Adolescence, 25, 392-420.

Schwartz, S. J., Pantin, H., Coatsworth, J. D., \& Szapocznik, J. (2007). Addressing the challenges and opportunities for today's youth: Toward an integrative model and its implications for research and intervention. The Journal of Primary Prevention, 28, 117-144.

Schwartz, S. J., Zamboanga, B. L., Weisskirch, R. S., \& Wang, S. C. (2010). The relationships of personal and cultural identity to adaptive and maladaptive psychosocial functioning in emerging adults. Journal of Social Psychology, 150, 1-33.

Soenens, B., Berzonsky, M. D., Vansteenkiste, M., Beyers, W., \& Goossens, L. (2005). Identity styles and causality orientations: In search of the motivational 
underpinnings of the identity exploration process. European Journal of Personality, 19, 427-442.

Sue, S., \& Zane, N. (Eds.). (2006a). Ethnic minority populations have been neglected by evidence-based practices. In J. C. Norcross, L. E. Beutler, \& R. F. Levant (Eds.). Evidence-based practices in mental health: Debate and dialogue on the fundamental questions (pp. 338-345; 359-361). Washington, DC: American Psychological Association.

Waterman, A. S. (1984). Discovery or creation? Journal of Early Adolescence, 4, 329-341.

Waterman, A. S. (1993). Two conceptions of happiness: Contrasts of personal expressiveness (eudaimonia) and hedonic enjoyment. Journal of Personality and Social Psychology, 64, 678-691.

Waterman, A. (2005). When effort is enjoyed: Two studies of intrinsic motivation for personally salient activities. Motivation and Emotion, 29, 165-188.

Waterman, A. S. (2007a). Doing well: The relationship of identity status to three conceptions of well-being. Identity: An International Journal of Theory and Research, 7, 289-307.

Waterman, A. S. (2007b). Introduction to the special issue: Psychosocial identity and well-being. Identity: An International Journal of Theory and Research, 7, 263-264.

Zimmerman, M.A. (1995). Psychological empowerment: Issues and illustrations. American Journal of Community Psychology, 23, 581-599. 


\section{APPENDICES}

Figure 1: Outcome Mediation Cascade (OMC) Model

OUTCOME EVALUATION MODEL

SINGLE INTERVENTION COMPONENT, SINGLE OUTCOME DOMAIN
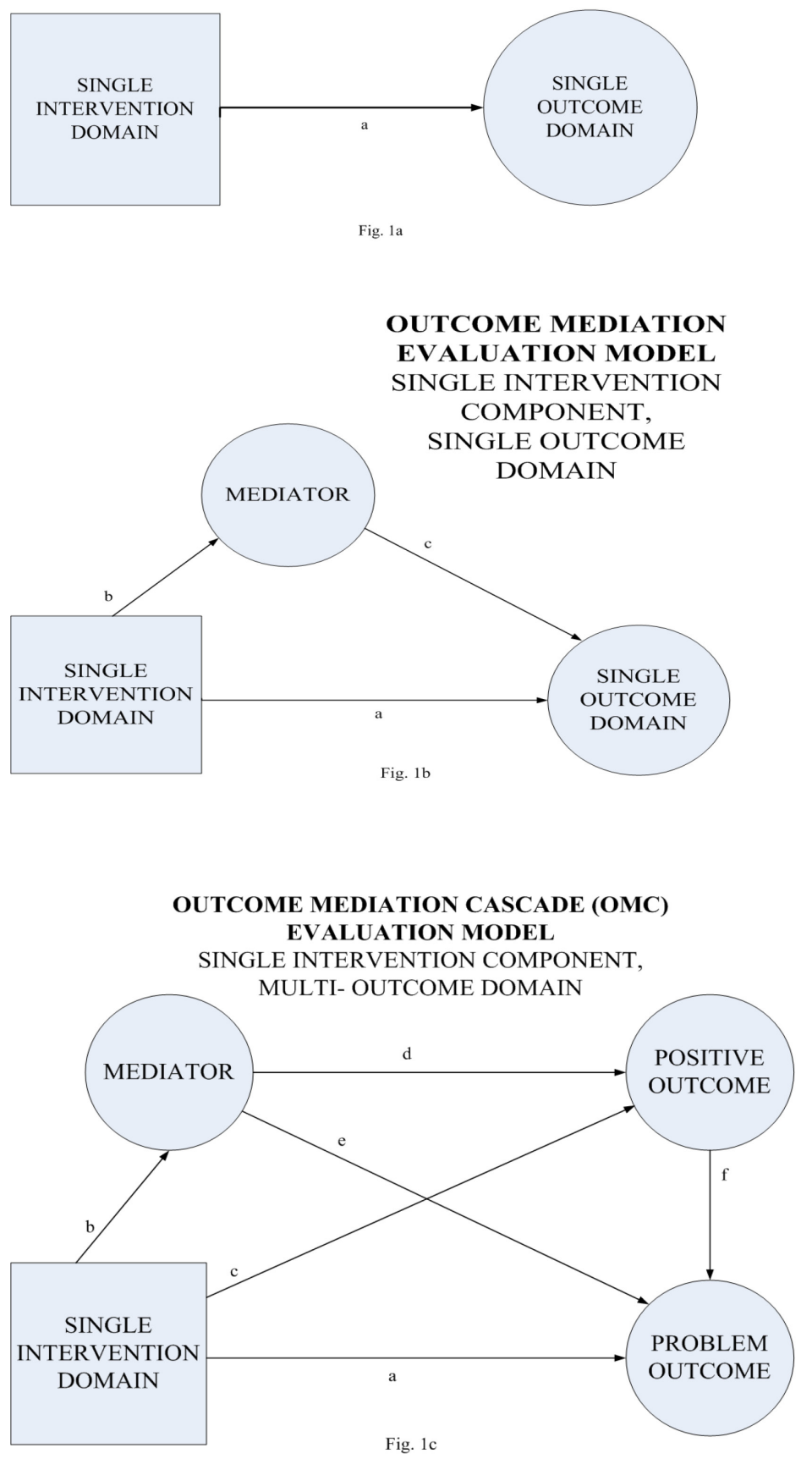
Figure 2: Conceptual Model

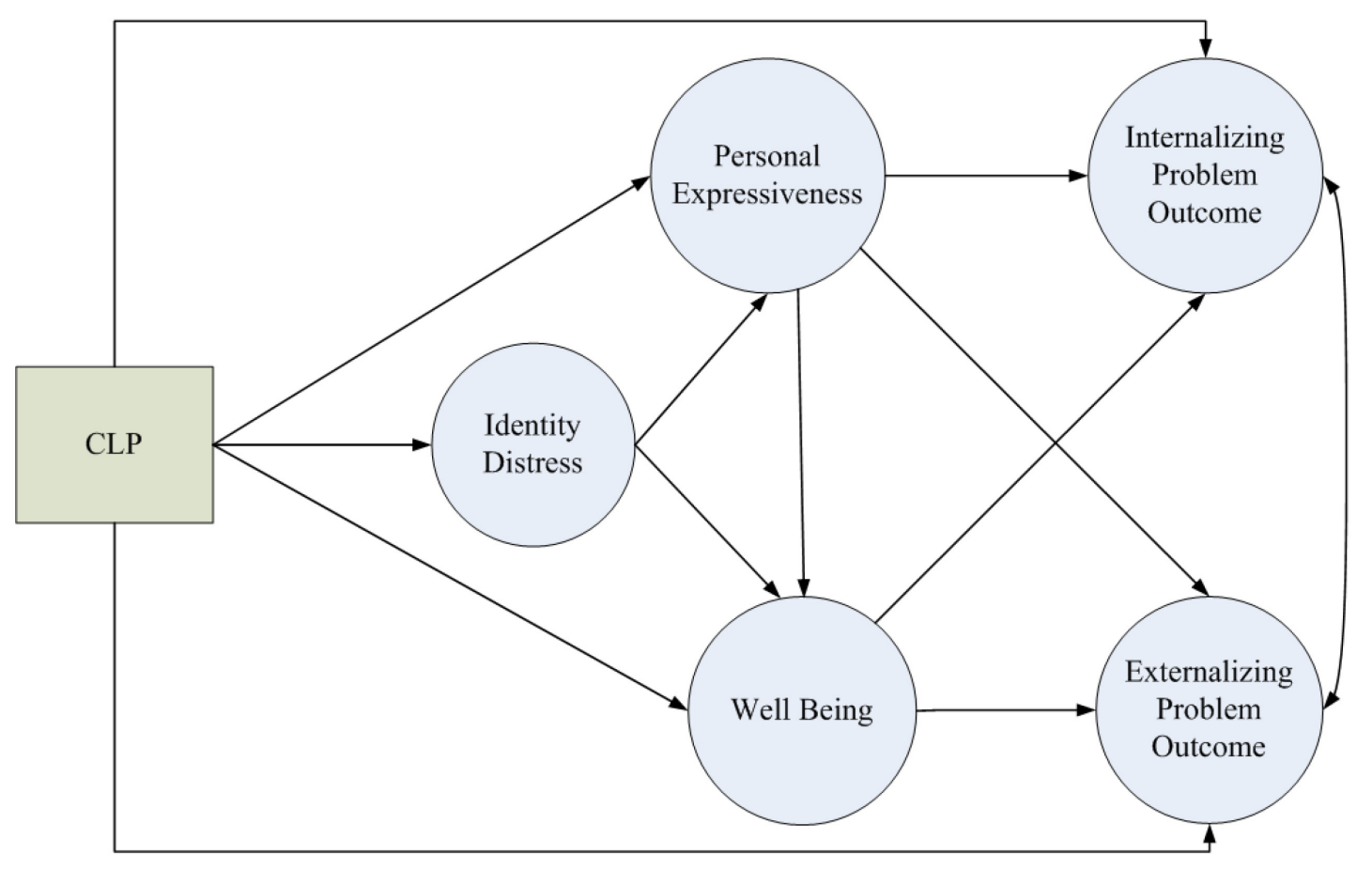


Figure 3: Hypothesized Effects

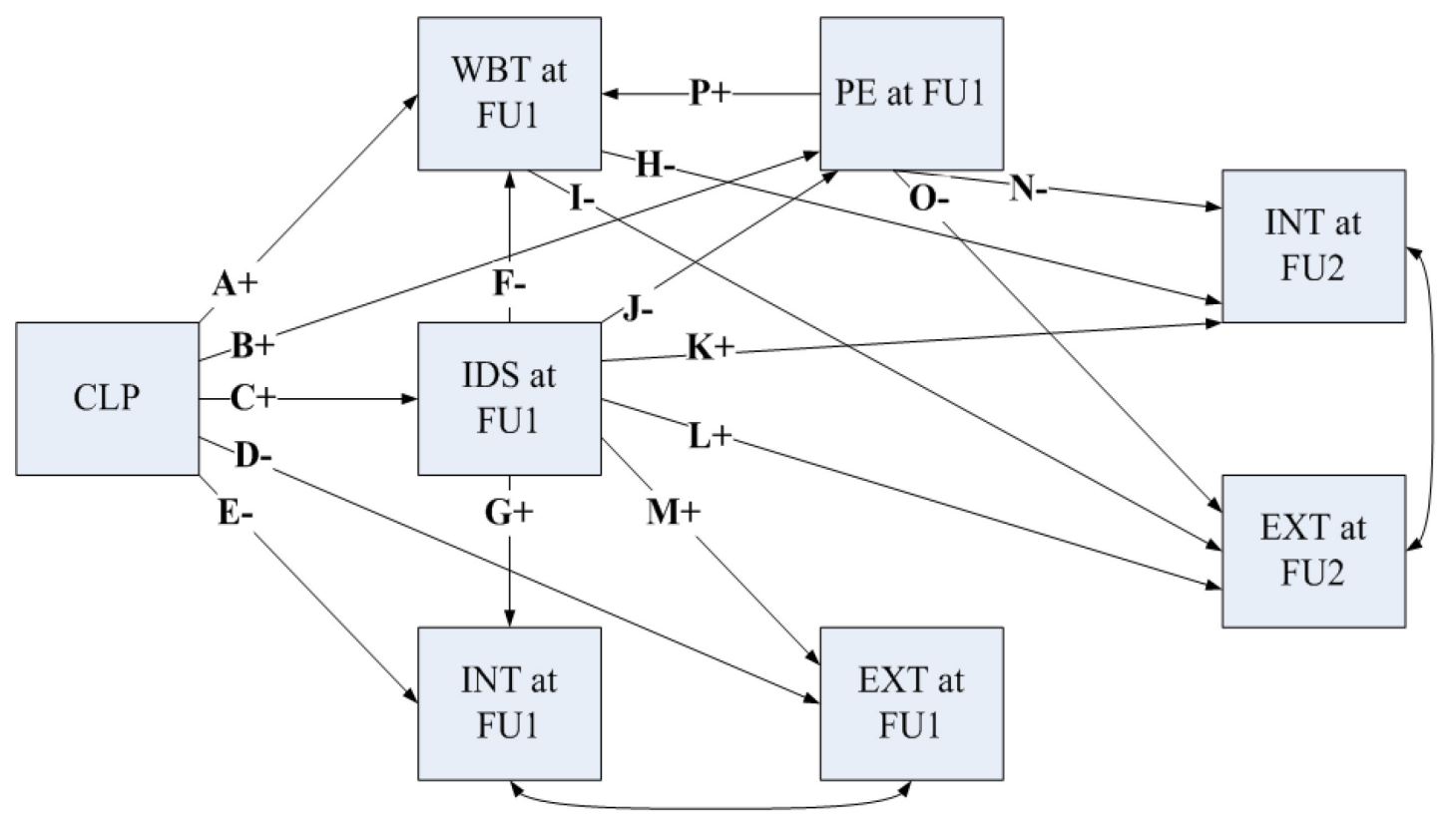


Figure 4: OMC Model Results

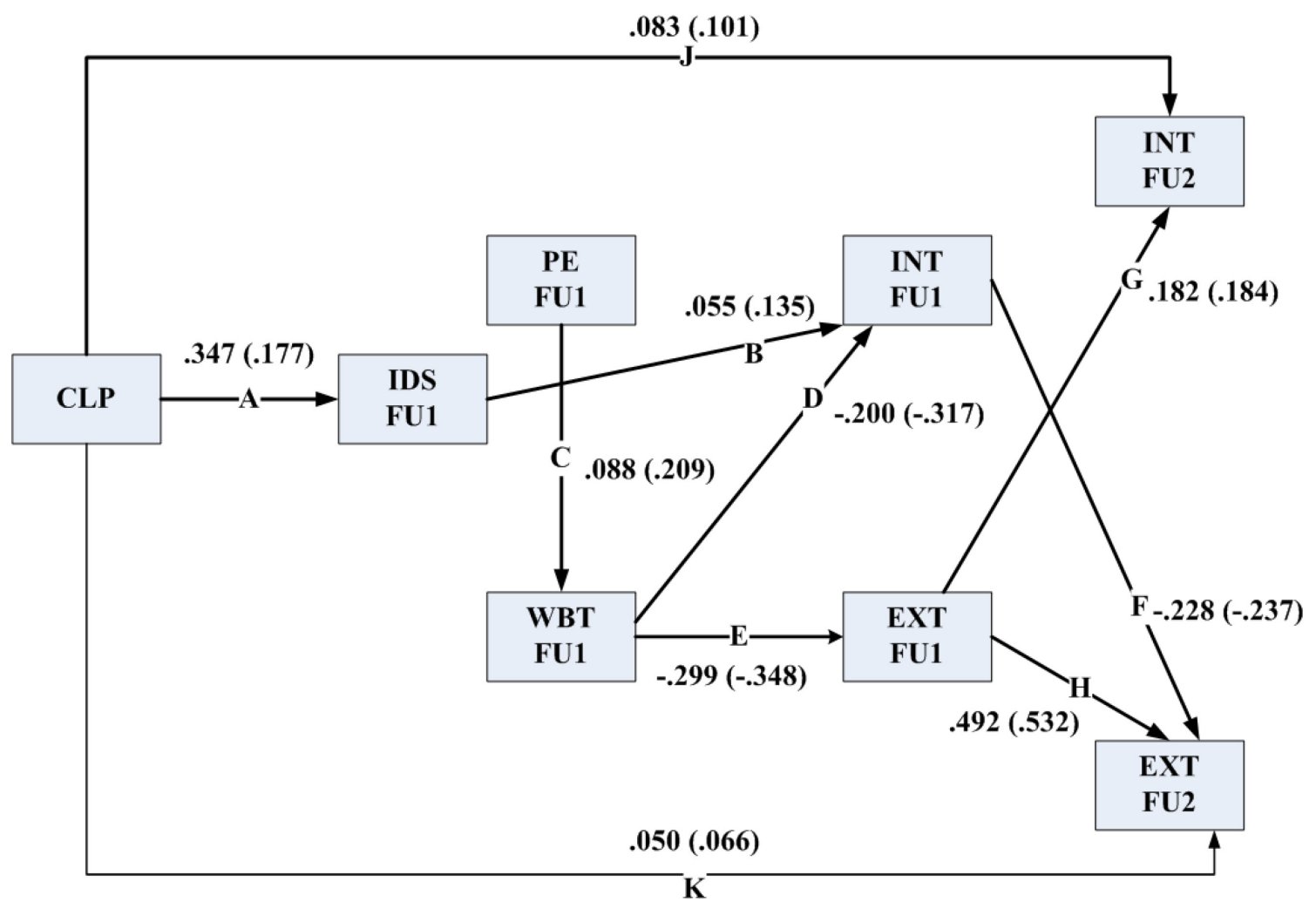

Note: Paths in bold denote significance at $p<.05$. Non-bold paths denote marginal significance $(p<.10)$ 
Table 1: Descriptive Statistics for model variables $(N=238)$

\begin{tabular}{|c|c|c|c|c|c|c|c|c|}
\hline \multirow[b]{2}{*}{ Variable } & \multicolumn{2}{|l|}{$M$} & \multicolumn{2}{|l|}{$S D$} & \multicolumn{2}{|l|}{ Skewness } & \multicolumn{2}{|c|}{ Kurtosis } \\
\hline & Pre & FU1 & Pre & FU1 & Pre & FU1 & Pre & FU1 \\
\hline Identity Distress (IDS) & 2.562 & 2.670 & .904 & 958 & .181 & .095 & -.486 & .441 \\
\hline $\begin{array}{l}\text { Personal } \\
\text { Expressiveness (PE) }\end{array}$ & 5.531 & 5.305 & 1.30 & 1.47 & -1.06 & -.736 & 1.01 & 182 \\
\hline \multirow[t]{3}{*}{ Well Being (WBT) } & 3.54 & 3.57 & .664 & .624 & -.397 & -.329 & .457 & .646 \\
\hline & $M$ & & $S D$ & & Skewness & & Kurto & \\
\hline & FU1 & FU2 & FU1 & FU2 & FU1 & FU2 & FU1 & FU2 \\
\hline $\begin{array}{l}\text { Internalizing Problem } \\
\text { Behaviors (INT) }\end{array}$ & 1.571 & 1.601 & .392 & .403 & .642 & .475 & .066 & 437 \\
\hline $\begin{array}{l}\text { Externalizing Problem } \\
\text { Behaviors (EXT) }\end{array}$ & 1.709 & 1.680 & .412 & .376 & .272 & .470 & -.671 & .160 \\
\hline
\end{tabular}

